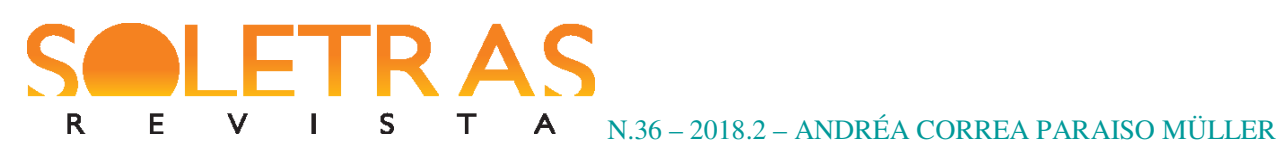

\title{
Uma voz deste século em busca de um lugar na literatura
}

\author{
Andréa Correa Paraiso Müller ${ }^{1}$
}

\begin{abstract}
Resumo: O romance $O$ caso Meursault (2016), escrito em francês pelo argelino Kamel Daoud, retoma, como se pode ver dede o título, o clássico $O$ estrangeiro (1942), de Albert Camus, porém o faz do ponto de vista da vítima. O narrador - o irmão mais novo do árabe assassinado por Meursault, protagonista e narrador de $O$ estrangeiro - expressa o desejo de reconstituir uma história silenciada e de restituir a voz e a identidade de seu irmão, que não tivera nome no relato de Meursault. Lido por muitos como metáfora da colonização francesa na Argélia, o romance de Daoud vai muito além de uma revisão do passado. Questiona o presente de seu país e põe em foco a própria literatura. Este artigo tem por objetivo realizar uma análise da construção intertextual de $O$ caso Meursault - para a qual nos apoiamos, sobretudo, em propostas teóricas de Gignoux (2016) e Samoyault (2008) - aliada à reflexão sobre as questões pós-coloniais, com base em autores como Clavaron (2012), Achour (2015), Said (1990), entre outros. Procuramos entender o texto de Daoud não simplesmente como um exemplar da produção romanesca de seu país e das questões sociais e políticas envolvidas, mas, principalmente, como expressão da literatura de seu tempo.
\end{abstract}

Palavras-chave: Intertextualidade. Romance. Literatura contemporânea. Kamel Daoud.

\section{Introdução}

Meursault, contre-enquête, traduzido no Brasil como $O$ caso Meursault (Biblioteca Azul, 2016), é o primeiro romance do escritor e jornalista argelino Kamel Daoud. Escrito originalmente em francês e lançado na Argélia em 2013 (Éditions Barzakh) e na França em 2014 (Actes Sud), conquistou considerável sucesso e já foi traduzido para mais de vinte idiomas. Obteve uma recepção bastante positiva na França, onde concorreu ao prestigioso prêmio Goncourt, tendo sido laureado na categoria Primeiro Romance (Goncourt du premier roman, 2015).

O título do romance, tanto no original quanto na tradução para o português do Brasil, chama a atenção: quem conhece a obra de Albert Camus ou se interessa pela literatura do século XX certamente associa o título a um dos romances mais conhecidos do escritor francoargelino e da prosa francesa novecentista: O estrangeiro (1942). O nome singular do narrador personagem de Camus estampado no título do romance de estreia de Daoud sinaliza a intertextualidade. E, logo no início do texto, o diálogo se confirma.

\footnotetext{
${ }^{1}$ Doutora em Teoria e História Literária pela Unicamp. Professora do Departamento de Estudos da Linguagem da Universidade Estadual de Ponta Grossa - PR (UEPG). Docente permanente do Programa de Pós-graduação em Estudos da Linguagem da UEPG, Ponta Grossa, PR, Brasil. E-mail: andrea.paraiso@uol.com.br.
} 
O caso Meursault é narrado em primeira pessoa pelo protagonista Haroun, irmão mais novo do árabe assassinado por Meursault em $O$ estrangeiro. No romance de Camus, o morto não tem nome nem história, nada se diz sobre ele. $\mathrm{O}$ assassinato desencadeia transformações na vida e no pensar de Meursault, em sua própria maneira de narrar. Mas nada se diz sobre a vítima; ela parece importar pouco para a justiça que condena Meursault, assim como para o desenrolar da narrativa. Daoud cria um nome, Moussa, uma família e uma história para o homem morto. Ele era o arrimo de sua família após o desaparecimento do pai; seu assassinato deixa desamparados a mãe e o irmão mais novo. E é justamente esse irmão mais novo, Haroun, criança quando da morte de Moussa, que vai narrar, mais de cinquenta anos depois, não só a sua visão dessa história, mas a maneira como ela influenciou seus atos na juventude.

Haroun crescera suportando o ódio e a loucura da mãe, atormentada pelo assassinato do filho mais velho por um francês. Essa história acompanha sua vida de tal forma, que chega a limitá-la. Na juventude, descobre a narrativa de Meursault. Sim, de Meursault; no romance de Daoud, o nome de Camus não é mencionado em momento algum, e o narrador Haroun referese à obra como sendo de Meursault. Ele se revolta com o anonimato ao qual é reduzido seu irmão:

Devo dizer que é uma história que remonta a mais de meio século. Ela aconteceu de fato, e foi muito comentada. As pessoas ainda falam dela, mas, com o maior descaramento, evocam apenas um morto, sendo que havia dois: não um morto, mas mortos. Sim, dois. Qual o motivo dessa omissão? O primeiro deles sabia contar histórias, a tal ponto que conseguiu fazer com que o seu crime fosse esquecido, enquanto o segundo era um pobre analfabeto que Deus pôs no mundo, ao que parece, unicamente para levar um tiro de revólver e retornar ao pó, um anônimo que não teve nem sequer tempo de ter um nome (DAOUD, 2016, p. 9).

E é por isso que decide narrar, para dar voz ao irmão morto e a tudo o que foi silenciado em uma história conhecida: "Quem é Moussa? É meu irmão. E é aí que eu quero chegar. Quero lhe contar o que Moussa nunca poderá contar” (DAOUD, 2016, p. 12).

Muito mais do que a história de seu irmão, é a sua própria história que Haroun narra. E, à medida que vai tecendo seu relato, deixa perceber semelhanças cada vez mais evidentes entre a sua trajetória e a de Meursault. Assim como o narrador de $O$ estrangeiro, também Haroun comete um assassinato. Meursault matara um árabe que ele não conhecia; Haroun mata um francês, também desconhecido. O crime de Haroun acontece em 1962, logo depois 
do final da longa e sangrenta guerra que libertou a Argélia da colonização francesa. As trajetórias dos dois narradores chegam quase a espelhar-se, e o sentido de $O$ caso Meursault, assim como a profunda reflexão que o romance provoca, constrói-se calcado no diálogo com O estrangeiro.

Outras obras de Camus também são solicitadas pelo romance de Daoud. La Chute (1956), por exemplo, parece ressoar na composição da narrativa de Haroun: este último, já idoso, conta sua história a um estudante em um bar da cidade argelina de Orã; caberá a esse estudante escrever o relato transmitido oralmente. A situação lembra a de Jean-Batiste Clamence, protagonista de $\mathrm{La}$ Chute, que constrói sua narrativa em forma de monólogo dirigido a um homem em um bar de Amsterdam. Há estudos que consideram $O$ caso Meursault como pastiche de La Chute (LOUAIL, 2016). No entanto, é com O estrangeiro que se estabelece um diálogo mais direto, cujas marcas se deixam identificar de maneira mais contundente desde o título.

Kamel Daoud não é o único nem o primeiro escritor argelino francófono a revisitar Albert Camus. Seu romance faz parte do que Christiane Achour chama de "conjunto impressionante de referências argelinas a Camus" (ACHOUR, 2015). Destaca-se entre as diversas obras que alargaram esse conjunto em 2013, quando do centenário de nascimento do autor de $O$ estrangeiro (LOUAIL, 2016).

A partir do diálogo com Camus, $O$ caso Meursault interroga as memórias da relação entre França e Argélia, as dores da colonização e o lugar da língua francesa na produção literária argelina. E, ao abordar todas essas questões, põe em foco a própria literatura.

$\mathrm{Na}$ sequência deste artigo, discutiremos primeiramente os procedimentos intertextuais que compõem o jogo de espelhos com $O$ estrangeiro e, em seguida, refletiremos sobre $O$ caso Meursault no contexto da literatura argelina francófona.

\section{A construção intertextual}

Se o leitor que se depara com o título $O$ caso Meursault ainda tiver dúvidas quanto à relação com $O$ estrangeiro, ao abrir o livro as evidências vão-se fortalecendo. $\mathrm{O}$ romance inicia-se com uma frase imensamente sugestiva para os leitores de Camus: "Hoje, mamãe continua viva" (DAOUD, 2016, p. 9). Referência evidente à famosa abertura de $O$ 
estrangeiro, em que Meursault anuncia a morte da mãe: "Hoje, mamãe morreu" (CAMUS, 2017, p. 13).

O leitor de $O$ estrangeiro encontrará inúmeras referências explícitas como essa. Não são citações, mas passagens que remetem ao romance de Camus e apelam para a memória do leitor. Passagens que aproximam Haroun de Meursault, que colocam suas narrativas e suas trajetórias em paralelo. Os detalhes que cercam o crime cometido por Haroun, por exemplo, remetem a certos detalhes relacionados ao crime de Meursault. Quando Haroun vê pela primeira vez o francês que ele viria a assassinar, também há um sol forte e um calor que o perturbam, assim como havia na famosa cena de $O$ estrangeiro em que Meursault mata o árabe: "Naquela tarde, havia no céu um sol ofuscante, grande e pesado, e o calor insuportável me embaralhava a mente" (DAOUD, 2016, p. 99). E a reflexão dos narradores após cometerem assassinato compara o crime, nos dois casos, a uma ruptura do equilíbrio: "Eu sentia minha pele gelada sob o braço direito, aquele que acabara de romper o equilíbrio das coisas" (DAOUD, 2016, p. 92). "Compreendi que destruíra o equilíbrio do dia" (CAMUS, 2017, p. 60).

Após matar o francês, Haroun sente-se por um instante aliviado, como se tivesse finalmente cumprido o que sua mãe sempre o pressionara de alguma forma para fazer. $\mathrm{O}$ assassinato de um francês logo após a libertação da Argélia do domínio da França parece simbolizar essa liberdade. Mas Haroun não se sente livre dos franceses, e sim de sua mãe, da obsessão que ela alimentava desde a morte de Moussa. E reflete: "Pela minha mente passava a ideia de que eu finalmente poderia ir ao cinema ou nadar com uma mulher" (DAOUD, 2016, p. 93). Em $O$ estrangeiro, Meursault nada no mar com a namorada Maria e vai ao cinema com ela após o enterro da mãe. Os tiros foram, para Haroun, "batidas na porta da libertação": "Foram como duas batidas rápidas na porta da libertação" (DAOUD, 2016, p. 102). Para Meursault, haviam sido batidas na porta da infelicidade: "E era como se desse quatro batidas secas na porta da desgraça” (CAMUS, 2017, p. 60).

Todas essas alusões em $O$ caso Meursault só são perceptíveis ao leitor que conhece $O$ estrangeiro. Somente quem leu o romance de Camus pode lembrar-se do quão perturbadores eram o sol e o calor para Meursault, ou ainda da sua observação sobre a destruição do equilíbrio do dia. Somente um leitor de Camus poderá enxergar uma oposição entre as batidas na porta da libertação de Haroun às batidas na porta da desgraça de Meursault. Não são 
citações, não estão entre aspas, não reproduzem palavras exatas, mas fazem apelo à memória do leitor; fazem sentido para um leitor que tenha lido $O$ estrangeiro.

Tiphaine Samoyault, ao abordar as práticas intertextuais, diferencia referências e alusões. A referência, segundo a autora, "não expõe o texto citado, mas a este remete por um título, um nome de autor, de personagem ou a exposição de uma situação específica" (SAMOYAULT, 2008, p. 50). Ora, as referências a $O$ estrangeiro em $O$ caso Meursault começam com o próprio título e podem ser percebidas até mesmo por um leitor que apenas tenha ouvido falar do romance de Camus sem nunca tê-lo lido. Já as passagens que mencionamos acima parecem estar mais para o terreno da alusão:

A alusão pode também remeter a um texto anterior sem marcar a heterogeneidade tanto quanto a citação. [...] Não plenamente visível, ela pode permitir uma convivência entre o autor e o leitor que chega a identificála. A alusão depende mais do efeito de leitura do que as outras práticas intertextuais: tanto pode não ser lida como pode também o ser onde não existe (SAMOYAULT, 2008, p. 50-51).

As alusões apontadas dependem do leitor, de sua bagagem, de sua memória. O leitor de $O$ estrangeiro pode identificar intertextualidade em diversas passagens de $O$ caso Meursault em que não são mencionados nomes ou lugares, mas evocam-se, muitas vezes de maneira sutil, reflexões, situações ou até mesmo construções linguísticas. No extrato a seguir, é impossível não se lembrar do "ça m’est égal” pronunciado tantas vezes por Meursault: "Sim, mamãe ainda está viva e isso me é completamente indiferente" (DAOUD, 2016, p. 51). No momento do processo contra Haroun pela morte do francês, este se pergunta do que poderiam acusá-lo se sempre servira sua mãe, o que pode ser visto como uma alusão ao processo contra Meursault, no qual o acusam mais por ter abandonado sua mãe em um asilo e não ter chorado no enterro dela do que por ter matado um homem. E quando Haroun é colocado na prisão, seus companheiros de cela são todos franceses; ao perguntarem por que está ali, responde que havia matado um francês. A cena remete, evidentemente, ao momento em que Meursault é preso e encontra, como colegas de cela, diversos árabes que lhe perguntam por que razão ele está ali, e ele responde que havia matado um árabe. A correlação entre as cenas só pode ser estabelecida por um leitor que conheça $O$ estrangeiro.

A intertextualidade em $O$ caso Meursault é perceptível, pois, a dois tipos de leitor: o que leu Camus e consegue perceber as muitas alusões, e o que não o leu, mas conhece-o pela 


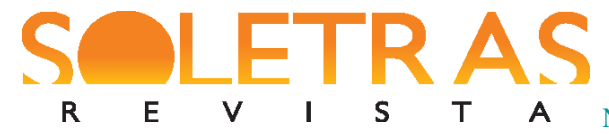

N.36 - 2018.2 - ANDRÉA CORREA PARAISO MÜLLER

tradição e é capaz de identificar nomes de personagens, lugares ou situações muito específicas. Ou seja, o reconhecimento da intertextualidade apela para a memória ou para a bagagem cultural do leitor. Há, no entanto, certas passagens do romance de Daoud que apontam para uma retomada de um texto anterior e podem ser identificadas até mesmo por um leitor que jamais tenha ouvido falar de $O$ estrangeiro ou de Camus, por mais que esse desconhecimento pareça improvável. São passagens como as que transcrevemos a seguir, nas quais é sugerida a existência de um texto anterior, um livro, uma história à qual o narrador se refere diversas vezes: "Você deve ter lido essa história tal como a contou o homem que a escreveu" (DAOUD, 2016, p. 10). "Eu também li a sua versão dos fatos. Como você e milhões de pessoas" (DAOUD, 2016, p. 11).

A intertextualidade se constrói, portanto, pela memória do leitor, pela bagagem cultural do mesmo, ou seja, pelo conhecimento de uma certa tradição literária mesmo sem ter lido o romance de Camus, mas também pela percepção de certas marcas textuais que apontam para a intertextualidade, mesmo que o texto retomado não seja reconhecido. A composição de $O$ caso Meursault alicerça-se, pois, sobre a intertextualidade. Trata-se de um texto que pode ser lido e apreciado sem que se conheça Camus, mas não sem que se perceba o recurso da relação com um texto anterior.

Acreditamos que $O$ caso Meursault, ao retomar $O$ estrangeiro, desenvolve um tipo de prática intertextual que Anne-Claire Gignoux designa, aliás bastante apropriadamente, como "rescritura" (GIGNOUX, 2016, p. 6). Diferente da reescritura, termo que a pesquisadora reserva para as reescritas de um mesmo texto pelo seu autor antes da publicação e que são objeto da crítica genética, a rescritura se refere à retomada deliberada por um autor de um texto já publicado, de sua própria autoria ou de outrem (GIGNOUX, 2016, p. 6). Uma simples alusão, segundo Gignoux, é intertextualidade, mas não necessariamente rescritura. Esta necessita de um leque de marcas tangíveis que formam um conjunto, estendendo-se ao longo do texto. A rescritura caracteriza-se por uma amplitude; afeta, pois, o texto como um todo (GIGNOUX, 2016, p. 7).

Em $O$ caso Meursault, as muitas alusões e referências dispostas ao longo do texto não são isoladas, mas compõem um todo, constroem o sentido do romance na relação deste com $O$ estrangeiro. Essa "rescritura" fica evidente nas muitas passagens em que Haroun declara retomar a narrativa de Meursault para recontá-la do ponto de vista dos que foram silenciados, de seu irmão, anônimo e ignorado: 


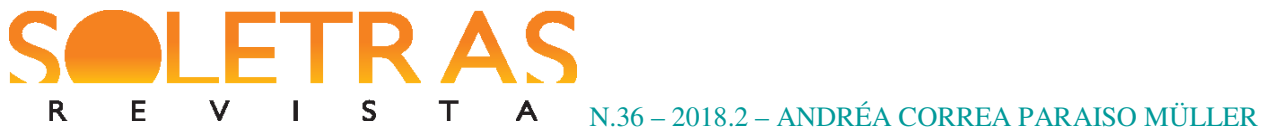

Aprendi essa língua, em parte, justamente para contar essa história no lugar do meu irmão, que era amigo do sol. Isso lhe parece inverossímil? Pois você se engana. Eu precisava encontrar a resposta que ninguém nunca quis me dar na hora devida. [...] Portanto, a história desse crime não começa com a famosa frase "Hoje mamãe morreu", mas sim com aquilo que nunca ninguém ouviu, quer dizer, o que meu irmão Moussa disse à minha mãe antes de sair de casa naquele dia: "Voltarei hoje mais cedo que o normal" (DAOUD, 2016, p. 15-19).

Haroun faz todo o seu relato, como já mencionamos, em um bar a um narratário com quem ele conversa e chama de "você", um estudante universitário que fora à Argélia para estudar a narrativa de Meursault, um romance, um livro ao qual o narrador alude várias vezes como sendo aquele em que seu irmão não tem nome. A autoria desse livro é atribuída ao próprio narrador personagem Meursault, ao qual Haroun se refere como "o seu herói" ou "o seu escritor". Por vezes, porém, parece que Meursault e Camus são fundidos em uma só pessoa, como na passagem em que Haroun afirma ter tido contato com outros livros "do seu escritor".

É possível entender as marcas intertextuais de $O$ caso Meursault como componentes de uma "rescritura" à medida que a trajetória toda de Haroun, assim como a sua narrativa, constituem uma espécie de espelho invertido da trajetória e da narrativa de Meursault, desde a relação dos narradores com suas mães até os processos pelos assassinatos. Meursault colocara a mãe em um asilo por não ter condições de mantê-la e também porque quase não se comunicavam mais, não tinham nada a dizer um ao outro; o romance já começa com a mãe morta. A mãe de Haroun, ao contrário, está viva e influencia sua vida fortemente com o ódio e a obsessão que a acompanham após a morte de Moussa. Assim como o narrador de $O$ estrangeiro, também Haroun é questionado por outros atos durante o processo pelo crime de morte que cometeu. Meursault é acusado mais por não ter chorado no enterro da mãe do que por ter matado um árabe. Haroun é acusado muito mais por não ter participado da guerra que expulsou os franceses do que por ter matado um francês. Aliás, é bastante questionado por ter matado o francês depois da guerra de libertação: se fosse durante, teria sido um ato heroico; como foi depois, reduz-se a um crime comum. O absurdo do processo parece repetir-se. $\mathrm{E}$ as reflexões de Haroun aproximam-se do sentimento de absurdo que é uma das tópicas mais discutidas pelos estudiosos de Camus: "Essa desproporção entre a minha insignificância e a 
vastidão do mundo me choca. Costumo dizer a mim mesmo que deve existir alguma coisa no meio, entre a minha banalidade e o universo!"' (DAOUD, 2016, p. 159).

Trajetórias que se espelham, narrativas que dialogam. Ao revisar, contrariar, reescrever a narrativa de Meursault, Haroun se descobre nela:

Esse homem, o seu escritor, parecia ter roubado de mim o meu gêmeo, Zoudj, meu retrato e até mesmo os detalhes de minha vida e as lembranças do meu interrogatório! [...] Era uma brincadeira perfeita. Eu procurei ali marcas do meu irmão e encontrei o meu próprio reflexo, vendo-me quase como um sósia do assassino (DAOUD, 2016, p. 151).

\section{O caso Meursault e a figurativização da literatura argelina de língua francesa}

A literatura magrebina ${ }^{2}$ de língua francesa é algo relativamente recente, que surge por volta de 1920 e consolida-se após a Segunda Guerra Mundial, mais precisamente nos anos 1950 (LAMEIRINHA, 2013, p. 24; RAQBI, 2017, p. 108). Foi inicialmente chamada de literatura magrebina de expressão francesa, de grafia francesa e, posteriormente, de língua francesa (LAMEIRINHA, 2013, p. 24), sendo também designada como literatura magrebina francófona. Esta última designação, no entanto, é tida como problemática por intelectuais que enxergam no termo "francofonia" um ranço da dominação colonial (SILVA, 2015, p. 127132).

Essa produção constituiu-se, em grande medida, como uma literatura de denúncia e de combates. Um dos temas mais recorrentemente abordados pelos escritores, sobretudo na Argélia, é a colonização, com suas consequências no terreno identitário: "Les auteurs qui avaient aborde ce thème [a colonização] insistaient sur la mutilation de leur identité, sur lês rapports dominants/dominés"3 (RAQBI, 2017, p. 108). Essa literatura surge e se desenvolve justamente em simultaneidade com o fortalecimento dos movimentos nacionalistas em prol da independência (LAMEIRINHA, 2013, p. 57).

\footnotetext{
${ }^{2}$ A região geográfica conhecida como Magrebe situa-se no norte da África e compreende cinco países: Argélia, Tunísia, Marrocos, Líbia e Mauritânia. No entanto, quando falamos em literatura magrebina de língua francesa, referimo-nos aos três primeiros, devido aos diversos aspectos históricos, culturais e literários que eles partilham. Apesar das semelhanças, não se pode estudar as literaturas da região como se formassem um todo homogêneo; é preciso considerar as particularidades da produção de cada país. Cristianne Lameirinha (2013, p. 58) concorda com Charles Bonn (1982), segundo o qual não haveria uma literatura magrebina única, sendo mais adequado falar em literatura argelina, literatura tunisiana e literatura marroquina.

3 "Os autores que abordaram esse tema [a colonização] insistiam sobre a mutilação de sua identidade, sobre as relações dominantes/dominados" (tradução nossa).
} 
Raqbi (2017, p. 118) distingue, grosso modo, três fases na trajetória da literatura magrebina de língua francesa. A primeira teria sido marcada pela denúncia da colonização e pela busca de identidade. A segunda teria como traços principais o prosseguimento das questões identitárias e o questionamento da língua e das normas tradicionais de escrita. A revolta contra as injustiças do colonialismo e a reflexão sobre o sentimento de bastardia ao escrever na língua do outro também estariam fortemente presentes nessa segunda fase. Já a terceira corresponde, segundo Raqbi, ao momento presente, caracterizando-se principalmente pela preocupação com os problemas da sociedade atual.

A ampliação e o aprimoramento de uma produção romanesca nos países do Magrebe marcam a consolidação dessa literatura nos anos 1950. Em Cultura e imperialismo, Edward Said sublinha a relevância da narrativa de ficção na trajetória do imperialismo e do colonialismo europeus, tanto do ponto de vista do colonizador quanto do lado do colonizado:

[...] as histórias estão no cerne daquilo que dizem os exploradores e os romancistas acerca das regiões estranhas do mundo; elas também se tornam o método usado pelos povos colonizados para firmar sua identidade e a existência de uma história própria deles (SAID, 2011, p. 11).

Na Argélia, o romance em língua francesa se desenvolve ao mesmo tempo em que se intensifica a luta pela independência do país. A temática da colonização é, portanto, marcante nos textos surgidos nesse período, embora não seja necessariamente abordada de maneira óbvia ou panfletária nem separada das preocupações com a construção textual (SILVA, 2015, p. 143).

Ao abordar a presença colonial francesa, os romancistas argelinos (mas também os dos demais países do Magrebe) do período da luta pela libertação e do pós-independência abordam também, de maneira intensa, a situação de exílio na língua francesa: "Os magrebinos, em contato com os europeus, sofrem o exílio da terra e da língua materna, uma vez que a maioria deles, ainda que tenha origem árabe ou berbere, tenha sido escolarizada em francês" (LAMEIRINHA, 2013, p. 30).

Tendo se instalado na Argélia no século $\mathrm{XIX}^{4}$ em busca de matéria-prima e mercados para o excedente de sua produção, a França estabeleceu ali uma colônia de povoamento. Os

\footnotetext{
${ }^{4}$ Não é propósito deste artigo traçar um panorama da história da dominação colonial francesa na Argélia; alguns fatos são mencionados à medida que se mostram indispensáveis para a compreensão do texto literário que 
chamados pieds-noirs, colonos franceses, recebiam ou compravam as terras que eram expropriadas dos nativos. É importante dizer que sempre houve resistência (YAZBEK, 2010, p. 18).

Para além da posse do território, a França levou à frente uma política de imposição de seus valores. O francês se tornaria o idioma oficial na Argélia. As escolas francesas promoviam a alfabetização em francês e o estudo da cultura francesa, em detrimento das línguas e culturas locais. As escolas corânicas, que difundiam a cultura árabo-islâmica, foram sendo reduzidas, na Argélia, até quase desaparecerem, o que privava os estudantes locais do aprendizado do árabe clássico, utilizado nos textos literários (LAMEIRINHA, 2013, p. 23). A língua francesa, aliada à escola, constituiu-se, portanto, em um forte instrumento de dominação, de assimilação cultural e de imposição dos valores ocidentais.

Alfabetizados em francês, muitos escritores argelinos das primeiras gerações experimentaram, como já mencionamos, uma condição de exílio na língua francesa ao terem de expressar suas percepções de mundo e mesmo sua visão da colonização na língua do colonizador. Assim, o processo de formação e consolidação da literatura argelina de língua francesa é marcado pelo aprofundamento da questão identitária decorrente do impasse entre o texto literário e o instrumento de sua construção - a língua do outro:

Para os escritores magrebinos, trata-se de escrever não só em uma língua estrangeira, mas de fazê-lo - especialmente na Argélia - sob a égide de uma cultura alheia à cultura local, cuja complexidade advém da mescla atemporal de componentes linguísticos e sociais de origem variada, isto é, cabila, berbere, árabe, judaica e europeia não francesa, somados ao islamismo como religião dominante. [...] A literatura magrebina de língua francesa situa-se no hiato estabelecido pela colonização frente à língua, que tem na identidade seu problema fundamental (LAMEIRINHA, 2013, p. 55-56).

Raqbi (2015, p. 110) ressalta o sentimento de bastardia manifestado por muitos escritores dos períodos colonial e pós-colonial cujos textos literários surgem como frutos, ao mesmo tempo, do convívio e do enfrentamento entre a língua de expressão - o francês - e a(s) língua(s) do pensamento - o árabe e o berbere. Kateb Yacine, considerado um dos fundadores da literatura argelina de língua francesa, abordou de maneira contundente essa temática. Proclamando a língua francesa como seu "espólio de guerra" (“butin de guerre”), fez dela,

abordamos. Para um maior aprofundamento no assunto, recomendamos consultar YAZBEK, Mustafa. A Revolução Argelina. São Paulo: Ed. UNESP, 2010. 
como bem observa Achour (2017, p. 6), uma ferramenta de questionamento do sistema à medida que se apropriou da mesma e a utilizou a partir do seu olhar e de sua cultura. Diferentemente dos que acreditavam que escrever em francês era uma espécie de traição à língua árabe, para Yacine, produzir literatura na língua do outro não significava alienação, mas afirmação:

Para Kateb, a língua francesa é a última herança deixada aos que viriam participar das lutas por uma Argélia livre e aberta ao mundo [...], deixando de ser um instrumento de alienação, mas uma pilhagem, usada para dizer ao colono as suas aspirações em torno duma liberdade roubada (SILVA, 2015, p.142).

A língua francesa, manejada pelos escritores argelinos das primeiras gerações é "arma de guerra ideológica" (SILVA, 205, p. 16), meio de se fazer ouvir pelo Ocidente, de se colocar e de cunhar um espaço para sua literatura.

Após a declaração de independência, em 1962, a Argélia passa por uma política de arabização, que busca excluir a língua francesa da esfera público-administrativa do país e restaurar o lugar que a língua árabe havia perdido com a colonização. No entanto, o francês não desaparece da literatura: mesmo após a independência, continua a surgir, na Argélia, uma importante produção literária em língua francesa.

Nos primeiros anos do período pós-colonial, as questões identitárias ainda estavam fortemente presentes nessa literatura. Pode-se afirmar, concordando com Silva (2015, p. 117) que a literatura dos primeiros anos após a independência era quase indissociável das questões histórico-políticas. A relação com o idioma de expressão era tematizada na escrita, assim como a guerra e todo o processo de independência. Escrever na língua do antigo colonizador continuava a despertar contradições e questionamentos dentro da própria escrita. Mais recentemente, no entanto, assistimos ao surgimento de novas gerações de escritores argelinos, que mantêm com a língua francesa uma relação diferente da de seus antecessores. Nascidos após a independência, não foram alfabetizados em francês e não tiveram esse idioma como imposição, mas como escolha:

Pour beaucoup d'auteurs de la nouvelle génération, n'ayant pas connu la colonisation ni la guerre, celle de l'Algérie en l'occurrence, le français est une langue d'élection, une langue d'adoption. Écrire en français pour ces auteurs n'est ni un drame ni un paradoxe, puisqu'ils écrivent dans une 
langue propre à eux, d'où leur rapport dépassionné avec ce qui est encore considéré par certains au Maghreb comme la langue de l'ancien colonisateur (EL OUARDINI, 2016, p. 75). ${ }^{5}$

É o caso de Kamel Daoud. Nascido em 1970, oito anos, portanto, após a declaração de independência, adota o francês por, entre outras razões, considerar que o árabe é hoje uma língua "fetichizada", "capturada" pelo sagrado e pelas ideologias dominantes (DAOUD, 2014 a). Mohamed Kacimi (2008 apud SILVA, 2015, p. 108) observa que escrever em francês representa, para muitos escritores magrebinos, uma ruptura do sagrado, que permite a emergência do "eu".

A geração de Daoud não se vê mais como produtora de uma escrita exilada na língua do ocupante. Ao autor de $O$ caso Meursault interessa discutir os problemas atuais de sua sociedade, bem como as questões que vão além de seu país, como a própria criação literária.A língua francesa não é mais um "espólio de guerra" como fora para os escritores que viveram o período colonial, mas um "bienvacant", um "imóvel desocupado" e pronto para ser reocupado e reconstruído:

Kateb Yacine parlait de butin, mais moi je ne suis pas um enfant de la guerre. C'est une histoire finie, je ne veux ni la porter ni la subir. Pour moi, la langue française est beaucoup plus un bien vacant, un bien sans maître. Je me la suis appropriée, mais ni par violence ni par la guerre. J'ai un rapport pacifié au français (DAOUD, 2014 b). ${ }^{6}$

A apropriação desse "imóvel vago" se faz presente nas palavras do narrador Haroun, que aprende o francês para narrar a história de seu irmão e a sua própria. Assim como as casas dos colonos franceses expulsos, a língua é um bem sem dono, as palavras são pedras de uma construção que pode ser remanejada, renovada, reconstruída:

Foi por isso, aliás, que aprendi a falar essa língua, e a escrever nela também: para falar por um morto, prolongar um pouco as frases dele. $\mathrm{O}$ assassino ficou famoso e a sua história é demasiadamente bem escrita para que eu

\footnotetext{
${ }^{5}$ Para muitos autores da nova geração, que não conheceram a colonização nem a guerra, a da Argélia no caso, o francês é uma língua de escolha, uma língua de adoção. Escrever em francês para esses autores não é nem um drama nem um paradoxo, pois escrevem em uma língua própria a eles, o que explica sua relação desapaixonada com o que ainda é considerado por alguns no Magrebe como a língua do antigo colonizador (Tradução nossa).

6 “Kateb Yacine falava de espólio, mas eu não sou filho da guerra. É uma história terminada, não quero carregala nem sofrê-la. Para mim, a língua francesa é muito mais um imóvel vago, um bem sem dono. Apropriei-me dela, mas não pela violência, nem pela guerra. Tenho uma relação pacificada com o francês" (Tradução nossa).
} 
pense em imitá-la. Era a língua dele. É por isso que farei o que se fez neste país depois da sua independência: pegar uma a uma as pedras das velhas casas dos colonos e erguer com elas uma casa minha, uma língua minha. As palavras do assassino e suas expressões são o meu imóvel desocupado (DAOUD, 2016, p. 10).

Jornalista e cronista profícuo desde os anos 1990, Kamel Daoud sempre defendeu as liberdades individuais em suas crônicas. Seu primeiro romance vai muito além de um acerto de contas com o passado colonial; reflete sobre a realidade atual de um país cujo sistema político ainda permanece sob forte influência dos que lutaram pela independência e que é governado, nos dizeres de Adam Schatz (2015), "como se a guerra jamais tivesse terminado".

O personagem-narrador Haroun se apropria das palavras do assassino para compor a sua língua, erguer seu discurso. "Ocupa" a língua do antigo colonizador para se fazer ouvir e narrar uma história silenciada, ou a parte silenciada de uma história conhecida:

É muito simples: essa história deveria ser, portanto, escrita na mesma língua, mas da direita para a esquerda. Ou seja: começando pelo corpo ainda vivo, as ruelas que o conduziram ao seu destino, o nome do árabe, até chegar ao seu encontro com a bala de um revólver. Aprendi essa em língua, em parte, justamente para contar essa história no lugar do meu irmão, que era amigo do sol. Isso the parece inverossímil? Pois você se engana. Eu precisava encontrar uma resposta que ninguém nunca quis me dar na hora devida. Uma língua a gente bebe e fala, e um dia ela se apossa de você; então, ela se habitua a captar as coisas no seu lugar, toma conta da sua boca, como um casal faz em um beijo caloroso (DAOUD, 2016, p. 15).

Escrever a mesma história "da direita para a esquerda" remete à língua árabe. Haroun não escreve a história de seu irmão em árabe, mas o faz do ponto de vista do árabe, de seu lugar e de sua cultura. Narra na língua do assassino para fazer emergir um ponto de vista anteriormente apagado.

Ao abordar a problemática da língua e dialogar com Camus pelo prisma dos silenciados da narrativa de Meursault, Daoud remete à trajetória da literatura argelina de língua francesa. Expressão de combates e de denúncias, que encontra na língua do opressor o instrumento para se fazer ouvir (LAMEIRINHA, 2013; RAQBI, 2015; SILVA, 2015), a literatura argelina de língua francesa das primeiras gerações ergue-se, muitas vezes, como resposta, como tomada de voz. Ao criar uma resposta a $O$ estrangeiro, Daoud figurativiza os combates dessa literatura. 
Para Schatz (2015), na primeira parte de $O$ caso Meursault, Daoud acerta as diferenças que os nacionalistas argelinos e os críticos pós-coloniais tinham em relação a Camus e a $O$ estrangeiro. Francês nascido na Argélia, filho de colonos, Camus foi criticado por intelectuais argelinos e, mais tarde, por pensadores do pós-colonialismo, como Edward Said, em razão de sua postura em relação à guerra de independência da Argélia $^{7}$ e pela representação dos árabes em suas obras. Edward Said reprovava o ponto de vista supostamente externo assumido por Camus para referir-se à presença francesa na Argélia:

\begin{abstract}
A ironia é que, em todos os romances ou textos descritivos em que Camus narra uma história, a presença francesa na Argélia é apresentada como uma narrativa externa, uma essência que não está sujeita ao tempo nem à interpretação [...]. O empedernimento de Camus explica o vazio e a ausência de qualquer contextualização do árabe morto por Meursault [...]. Tanto $\mathrm{O}$ estrangeiro quanto A peste tratam da morte de árabes, morte esta que realça e modela silenciosamente os problemas de consciência e reflexão dos personagens franceses (SAID, 2011, p. 286-288).
\end{abstract}

A geração pós-independência, à qual pertence Daoud, tem com a obra de Camus, como bem observa Achour (2015), uma relação diferente da que tinham os escritores da geração anterior. Ao criar uma resposta à negação e ao apagamento do árabe morto por Meursault, ultrapassa o simples acerto de contas: elabora uma obra original que reflete sobre a literatura argelina, reivindicando para essa literatura, a própria figura de Camus. Ao dialogar com $O$ estrangeiro e construir-se como uma resposta a ele (as muitas marcas intertextuais abordadas na primeira parte deste artigo evidenciam o diálogo), O caso Meursault revive a história da literatura argelina de língua francesa, problematizando e trazendo para o presente, por meio do olhar do presente, muitas das questões abordadas por seus antecessores, entre elas, a língua e a relação dessa literatura com Camus.

\title{
Considerações finais
}

Yves Clavaron (2011 apud ACHOUR, 2015, p. 5) entende o pós-colonial como uma releitura do discurso colonial, um contradiscurso que sublinha uma afirmação identitária antes

\footnotetext{
${ }^{7}$ Embora se opusesse ao colonialismo, Camus não se posicionou favoravelmente à guerra pela independência; propunha uma espécie de "pacto federativo", pelo qual conviveriam pacificamente na Argélia todas as comunidades que compunham o país (LAMEIRINHA, 2013, p. 65).
} 
negada, seja ela coletiva ou individual. Ao evidenciar esse contradiscurso, $O$ caso Meursault figurativiza a literatura de seu país, sobretudo aquela dos primeiros anos do período póscolonial. Encena e problematiza a história da literatura argelina de língua francesa por meio de um diálogo intertextual que aponta para o metaliterário. Mais do que um discurso circunscrito ao terreno do pós-colonial, o romance de estreia de Kamel Daoud trata também da literatura. Lido por muitos pesquisadores como uma metáfora da colonização francesa na Argélia (PISTER, 2015, p. 171), pode ser interpretado mais como metáfora da literatura argelina francófona, embora aborde também a literatura tout court.

Ao retomar $O$ estrangeiro, Daoud aborda e reinterpreta a literatura de seu país, situa nela sua voz, mas não somente nela. Ao reinterpretar seu tempo e ao confrontar Camus, toma não apenas a língua como um bienvacant, mas também a própria tradição literária, e não apenas a de seu país.

\section{Referências}

ACHOUR, Christiane Chaulet. La question de l'antériorité dans l'écriture. Albert Camus/KatebYacine/Kamel Daoud, 1942-2013. In: Colloque International la Littérature Maghrebine de Langue Française au Tournat du $21^{\text {ème }}$ Siècle, 1, 2015. Alger, Actes du Colloque, Alger, 2015, p. 1-9.

ACHOUR, Christiane Chaulet. Comme l'écrivait Kateb Yacine, le français est notre butin de guerre. Entretien à SimonaCrippa. Diacritik, L'Haÿ-les-Roses, 08 fev. 2017. Disponível em: http://diacritik.com. Acesso: 15 de janeiro de 2018.

BONN, Charles. Le roman algérien contemporain de langue française: espace de l'énonciation et productivité des récits. 1982. 1428 f. Tese (Doutorado) - Université de Bordeaux, France, 1982.

CAMUS, Albert. L'étranger. Paris : Gallimard, 1998.

La Chute. Paris: Gallimard, 2013.

O estrangeiro. Trad. Valérie Rumjanek. Rio de Janeiro: Bestbolso, 2017.

DAOUD, Kamel. O caso Meursault. Trad. Bernardo Ajzenberg. São Paulo: Biblioteca Azul, 2016.

DAOUD, Kamel. Interview. Le Figaro, Paris, 16 out. 2014. Disponível em:www.lefigaro.fr. Acesso em : 01 abr. 2018.

Kamel Daoud sur les traces de Camus. Interview. Le Point, Paris, 28 set. 2014.

Disponível em: http://afrique.lepoint.fr Acesso em: 28 mar. 2018. 


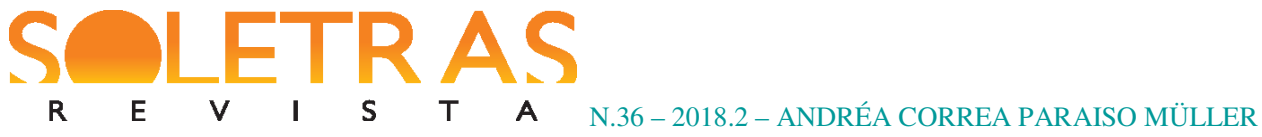

EL OUARDINI, Sanae. Kamel Daoud à la (pour)suíte de L'Étranger. Tropics: Revue électronique des Lettres et des Sciences Humaines de l'Université de la Réunion, La Réunion, n. 3, p. 67-76, 2016.

GIGNOUX, Anne-Claire. De l'intertextualité à la récriture. In: Cahiers de narratologie, Paris, n. 13, p. 1-12, set. 2016.

LAMEIRINHA, Cristianne Aparecida de Brito. Língua, exílio e memória. Uma leitura comparativa de Le premier homme, de Albert Camus e La disparition de la langue française, de Assia Djebar. 2013. 201 f. Tese (Doutorado em Estudos Linguísticos, Literários e Tradutológicos em Francês) - Universidade de São Paulo, São Paulo-SP, 2013.

LOUAIL, Massinissa. L'intertextualité dans le roman de Kamel Daoud Meursault, contreenquête, 2016. 70f. Mémoire (Master II) - Université d'Abderrahmne-Mira, Béjaïa-Argélia, 2016.

PISTER, Danielle. Meursault, contre-enquête : les miroitements d'un texte. Études littéraires africaines, Metz, n. 39, p. 168-173, 2015.

RAQBI, Ahmed. La littérature maghrébine d'expression française: littérature de déracinement et de dénonciation. Cerrados, Brasília, n. 43, v. 25, p. 104-118, 2015.

SAID, Edward. Cultura e imperialismo. Trad. Denise Bottmann. São Paulo: Companhia das Letras, 2011.

SCHATZ, Adam. Ainda estrangeiro. Trad. Sérgio Tellaroli. Revista Piauí, jul./2015.

SILVA, Wellington Rogério da. Representações do espaço na literatura magrebina contemporânea. 2015. 276 f. Tese (Doutorado em Letras) - Universidade Federal de Juiz de Fora, Juiz de Fora, MG, 2015.

YAZBEK, Mustafa. A revolução argelina. São Paulo: Ed. UNESP, 2010.

\section{A voice from this century seeking a place in the literature}

Abstract: The novel Meursault investigation (2016), written in French by the Algerian Kamel Daoud, resumes, as it can be seen from the title, the classic The Stranger (1942) by Albert Camus, but this time from the victim's standpoint. The narrator - the younger brother of the Arabian murdered by Meursault, main character and narrator in The Stranger - expresses the desire to rebuild a story that had been silenced and restore the voice and identity of his brother, whose name had not appeared in Meursault's narrative. Read by many as a metaphor of the French colonization in Algeria, Daoud's novel goes beyond a revision of the past. It questions the present of his country and focuses on the literature. This paper aims at developing an analysis of the intertextual construction of Meursault investigation - mainly 


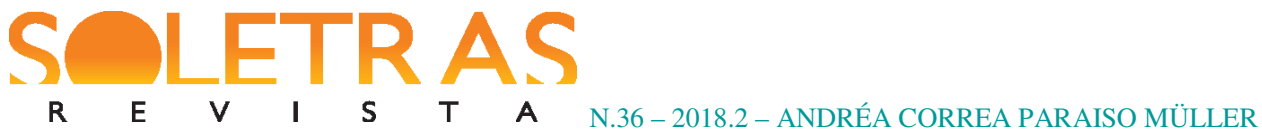

supported by the theoretical background by Gignoux (2016) and Samoyault (2008) - allied to the reflection on post-colonial issues based on Clavaron (2012), Achour (2015), and Said (1990), among others. We seek to understand Daoud's text, not only as a sample of the Romanesque production of his country and the social and political issues involved, but mainly as an expression of the literature of his time.

Keywords: Intertextuality. Novel. Contemporary literature. Kamel Daoud.

Enviado em: 02 de maio de 2018.

Aceito em: 30 de julho de 2018. 